\title{
A mulher quilombola e suas necessidades de cuidado: sob a ótica da literatura científica
}

\author{
The quilombola woman and their care needs: from the perspective of scientific literature \\ La mujer quilombola y sus necesidades de cuidado: desde la perspectiva de la literatura científica
}

Recebido: 20/01/2022 | Revisado: 24/01/2022 | Aceito: 28/01/2022 | Publicado: 29/01/2022

\author{
Zuleyce Maria Lessa Pacheco \\ ORCID: https://orcid.org/0000-0002-9409-8971 \\ Universidade Federal de Juiz de Fora, Brasil \\ E-mail: zuleyce.lessa@ufff.edu.br \\ Érika Andrade e Silva \\ ORCID: https://orcid.org/0000-0002-5752-7829 \\ Universidade Federal de Juiz de Fora, Brasil \\ E-mail: erikandradesilva@gmail.com \\ Beatriz Francisco Farah \\ ORCID: https://orcid.org/0000-0002-3345-0601 \\ Universidade Federal de Juiz de Fora, Brasil \\ E-mail: b-farah@hotmail.com \\ Geovana Brandão Santana Almeida \\ ORCID: https://orcid.org/0000-0003-3865-9727 \\ Universidade Federal de Juiz de Fora, Brasil \\ E-mail: geovanabrandao@yahoo.com.br \\ Carla Cardi Nepomuceno de Paiva \\ ORCID: https://orcid.org/0000-0001-6899-3262 \\ Centro Universitário Estácio de Sá, Brasil \\ E-mail: carlacardiufjf@gmail.com \\ Roseni Pinheiro \\ ORCID: https://orcid.org/0000-0001-8745-9209 \\ Universidade do Estado do Rio de Janeiro, Brasil \\ E-mail: rosenisaude@uol.com.br
}

\begin{abstract}
Resumo
Objetivo: descrever as necessidades de cuidado e saúde da mulher quilombola, na perspectiva da interseccionalidade de gênero, raça, corpo e política, segundo evidências publicadas na literatura científica. Método: Trata-se de uma revisão integrativa da literatura, cuja busca foi feita nas bases de dados: BVS, EBSCO, LILACS, SciELO, MEDLINE, Web of Science, Scopus, Applied Social Sciences Index \& Abstracts e na Biblioteca Digital Brasileira de Teses e Dissertações e Portal de Periódicos CAPES. Foram utilizados os descritores "Mulher quilombola", "Mulher Negra", "Vulnerabilidade", "Saúde", "Condições de saúde dos Grupos Étnicos", "Práticas de Cuidado", "Autocuidado", cujas combinações utilizadas com os operadores booleanos AND e OR. Foram utilizados como critérios de inclusão: artigos, teses e dissertações disponíveis gratuitamente nas bases de dados para leitura completa em português ou inglês, oriundos de pesquisas realizadas no Brasil e publicadas entre publicadas entre 2008 a 2018. Foram excluídas as publicações em formato de editoriais, debates e resenhas. Resultados: Foram analisadas 23 publicações inseridas em bases de dados nacionais, que delinearam as memórias dos modos de vidas das mulheres quilombolas, apontando para a saga da resistência e da luta contra o racismo, o patriarcado, o sexismo, a falta de acesso à saúde e o desrespeito às suas práticas culturais de cuidado ao longo dos dez anos da Política Nacional de Saúde Integral da População Negra. Conclusão: As publicações indicam as iniquidades sociais vivenciadas pelas mulheres quilombolas, reflexos das opressões cotidianas geradas pela interseccionalidade, requer maior atenção por parte das políticas de saúde e dos direito sociais.
\end{abstract}

Palavras-chave: Minorias Sexuais e de Gênero; Políticas Públicas; Saúde da Mulher; Sistema Único de Saúde.

\section{Abstract}

Objective: To describe the care and health needs of quilombola women, from the perspective of the intersectionality of gender, race, body, and politics, according to evidence published in the scientific literature. Method: This is an integrative literature review, which searched in the following databases: BVS, EBSCO, LILACS, SciELO, MEDLINE, Web of Science, Scopus, Applied Social Sciences Index \& Abstracts, and in the Brazilian Digital Library of Theses and Dissertations and CAPES Journal Portal. The descriptors "Quilombola woman", "Black Woman", "Vulnerability", "Health", "Health conditions of Ethnic Groups", "Care Practices", "Self-care", whose combinations 
used with the Boolean operators AND and OR. The following inclusion criteria: articles, theses, and dissertations available free in the databases for full reading in Portuguese or English, from research in Brazil published between 2008 and 2018. Publications in editorial format excluded debates and reviews. Results: Twenty-three publications analyzed in national databases, which outlined the memories of the ways of life of quilombola women, pointing to the saga of resistance and the fight against racism, patriarchy, sexism, lack of access to health, and the disrespect to their cultural care practices over the ten years of the National Policy for Comprehensive Health for the Black Population. Conclusion: The publications indicate the social inequities experienced by quilombola women, reflections of everyday oppression generated by intersectionality, requiring greater attention from health policies and social rights.

Keywords: Sexual and Gender Minorities; Health Policy; Women's Health; Unified Health System.

\section{Resumen}

Objetivo: Describir las necesidades de atención y salud de las mujeres quilombolas, desde la perspectiva de la interseccionalidad de género, raza, cuerpo y política, de acuerdo con evidencias publicadas en la literatura científica. Método: Se trata de una revisión de literatura integradora, que buscó en las siguientes bases de datos: BVS, EBSCO, LILACS, SciELO, MEDLINE, Web of Science, Scopus, Applied Social Sciences Index \& Abstracts, y en la Biblioteca Digital Brasileña de Tesis y Disertaciones y Portal de la Revista CAPES. Los descriptores "Mujer quilombola", "Mujer negra", "Vulnerabilidad", "Salud", "Condiciones de salud de los grupos étnicos", "Prácticas asistenciales", "Autocuidado", cuyas combinaciones se utilizan con los operadores booleanos Y y O. Los siguientes criterios de inclusión: artículos, tesis y disertaciones disponibles de forma gratuita en las bases de datos para lectura completa en portugués o inglés, de investigaciones en Brasil publicadas entre 2008 y 2018. Las publicaciones en formato editorial excluyeron debates y revisiones. Resultados: se analizaron 23 publicaciones en bases de datos nacionales, que delinearon la memoria de las formas de vida de las mujeres quilombolas, apuntando a la saga de la resistencia y la lucha contra el racismo, el patriarcado, el sexismo, la falta de acceso a la salud y la falta de respeto a la salud. sus prácticas de cuidado cultural durante los diez años de la Política Nacional de Salud Integral para la Población Negra. Conclusión: Las publicaciones señalan las inequidades sociales vividas por las mujeres quilombolas, reflejos de la opresión cotidiana generada por la interseccionalidad, requiriendo mayor atención por parte de las políticas de salud y derechos sociales.

Palabras clave: Minorías Sexuales y de Género; Política de Salud; Salud de la Mujer; Sistema Único de Salud.

\section{Introdução}

Os dados divulgados pelo Instituto Brasileiro de Geografia e Estatística (IBGE), em 2019, indicavam viver no país cerca de 108,4 milhões de mulheres, correspondendo a 51,6\% da população. Destas, 14,2 milhões autodeclaram-se brancas, 6,9 pretas, 1,1 amarelas, 41,4 pardas e aproximadamente 408 mil são indígenas. As mulheres são as principais usuárias do Sistema Único de Saúde (SUS) (Instituto Brasileiro de Geografia e Estatística, 2019).

As mulheres quilombolas estão expostas às desigualdades sociais que por vezes limitam seu acesso ao serviço de saúde. Para além da vulnerabilidade econômica, essa população vivencia na pele as opressões geradas pela interseccionalidade de seu cotidiano. Esta se materializa na desigualdade étnico-racial, no racismo, no patriarcado, no sexismo, na falta de acesso à saúde, as assimetrias de gênero, violências institucionais e sobretudo na descaracterização dessa mulher como um ser de direito e contrária aos princípios do sistema de saúde, que preconiza ser único, universal e igualitário (Grossi, Oliveira \& Oliveira, 2018; Fernandes, Galindo \& Valencia, 2020; Freitas et al.2011).

Compreende-se que a igualdade étnico-racial e de gênero são estruturantes no sistema de saúde, contudo, o racismo impede que todos sejam atendidos igualitariamente. Dessa forma, tais desigualdades são grandes obstáculos para o acesso às ações de promoção e prevenção de saúde das mulheres negras, o que tem impactado nas condições de vida e no processo de adoecimento (Prestes \& Paiva, 2016; Werneck, 2016).

O déficit na atenção à saúde das mulheres negras no atual sistema de saúde provoca iniquidades sociais que acometem seu estado de saúde. Um dos fatores incidentes está nas discriminações étnico-racial e de gênero, que colocam essas mulheres numa posição de desvantagem em inúmeras situações. Mulheres negras de etnia quilombola têm dificuldade de acesso aos serviços básicos de saúde e a políticas públicas eficazes para a superação das desigualdades (Werneck, 2016; Paranhos, 2016; Souza, Silva \& Costa, 2019) 
O direito à saúde quilombola traz consigo a necessidade de se incorporar, às práticas, os conhecimentos e experiências apreendidas por cada sujeito em seu território. Dessa forma, espera-se que se supere a dicotomia entre a academia e o conhecimento tradicional, como também se promova o contato desses saberes, a fim de contribuir para uma efetiva promoção do cuidado e da saúde, respeitando-se as especificidades e singularidades que os caracterizam (Durand, 2016)

A presente revisão propôs-se a realizar uma busca teórico-conceitual na literatura nacional, nos anos de 2008 a 2018 , sobre o contexto social e político do que é ser uma mulher quilombola e suas necessidades de cuidado à saúde na perspectiva da interseccionalidade gênero, raça, corpo e política, e sistematizar os principais eixos de análise encontrados. Espera-se fornecer informações importantes sobre o visto e o não visto na realidade investigada, além de favorecer novas possibilidades de investigação e de planejamento de ações de saúde, que poderão impactar na promoção em saúde, bem como na defesa dos direitos dessas mulheres ao acesso aos serviços de saúde e maior visibilidade nas políticas públicas.

\section{Metodologia}

Trata-se de uma revisão integrativa da literatura, esta consiste em sintetizar resultados de estudos empíricos e teóricos relacionadas a questão norteadora do estudo além de orientar a busca por esta literatura de maneira sistemática, exige um método rigoroso e ordenado de busca, análise e síntese dos dados. Organiza-se em seis etapas: 1) formulação da questão norteadora, 2) identificação de critérios pré-estabelecidos para o levantamento bibliográfico, 3) definição de termos a serem extraídos dos estudos selecionados, 4) avaliação crítica dos estudos incluídos, 5) categorização dos estudos/análise dos dados e 6) apresentação e síntese dos resultados (Casarin, et al. 2020; Sousa, et al., 2018).

Para a elaboração da questão norteadora de pesquisa foi utilizado o mnemônico $\mathrm{P}$ (população) $\mathrm{C}$ (conceito) $\mathrm{C}$ (contexto) (Melnyk \& Fineout-Overholt, 2011). A partir de tais componentes elaborou-se a seguinte questão norteadora da revisão "Qual é o conhecimento científico publicado a respeito da saúde das mulheres quilombolas no contexto social e político brasileiro, com base nas categorias de autocuidado, vulnerabilidade e direitos de acesso à saúde? ”.

Quadro 1. P-C-C mnemônico usado na revisão integrativa

\begin{tabular}{|l|l|}
\hline População $(\mathrm{P})$ & Mulheres quilombolas \\
\hline Conceito $(\mathrm{C})$ & Saúde, autocuidado, vulnerabilidade e direitos de acesso à saúde \\
\hline Contexto $(\mathrm{C})$ & Publicações fruto de pesquisas realizadas no Brasil \\
\hline
\end{tabular}

Fonte: Autoras.

Foram estabelecidos como critérios de inclusão: estudos que respondam à questão norteadora, incluindo artigos e teses, no idioma português e inglês, publicados entre janeiro de 2008 a dezembro de 2018, frutos de pesquisas produzidas no cenário brasileiro, com acesso gratuito e disponível na íntegra para leitura. Foram excluídas as publicações em formato de editoriais, debates e resenhas.

O levantamento bibliográfico foi realizado entre os meses de julho a setembro de 2019 e incluiu as seguintes bases de dados: BVS, Descubra (Serviço da Rede Sirius / Biblioteca da UERJ), Lilacs, SciELO, PubMed, Web of Science, Scopus, ASSIA, BDTD nacional e CAPES. Os descritores utilizados foram: saúde da mulher, grupo com ancestrais do continente africano, vulnerabilidade em saúde, promoção da saúde, integralidade em saúde, direito à saúde, acesso aos serviços de saúde. Nas estratégias de busca, foram utilizados termos de indexação específicos (Medical SubjectHeadings - MeSH; Descritores em Ciências da Saúde - DeCS) e marcadores booleanos "OR" e "AND". 
A figura 1 descreve o todo o processo realizado para identificação, seleção, elegibilidade e inclusão das publicações, segundo os critérios de exclusão e inclusão dos registros selecionados para integrar a análise final do material da pesquisa.

Figura 1. Fluxograma do processo de seleção dos artigos, com base na recomendação PRISMA.

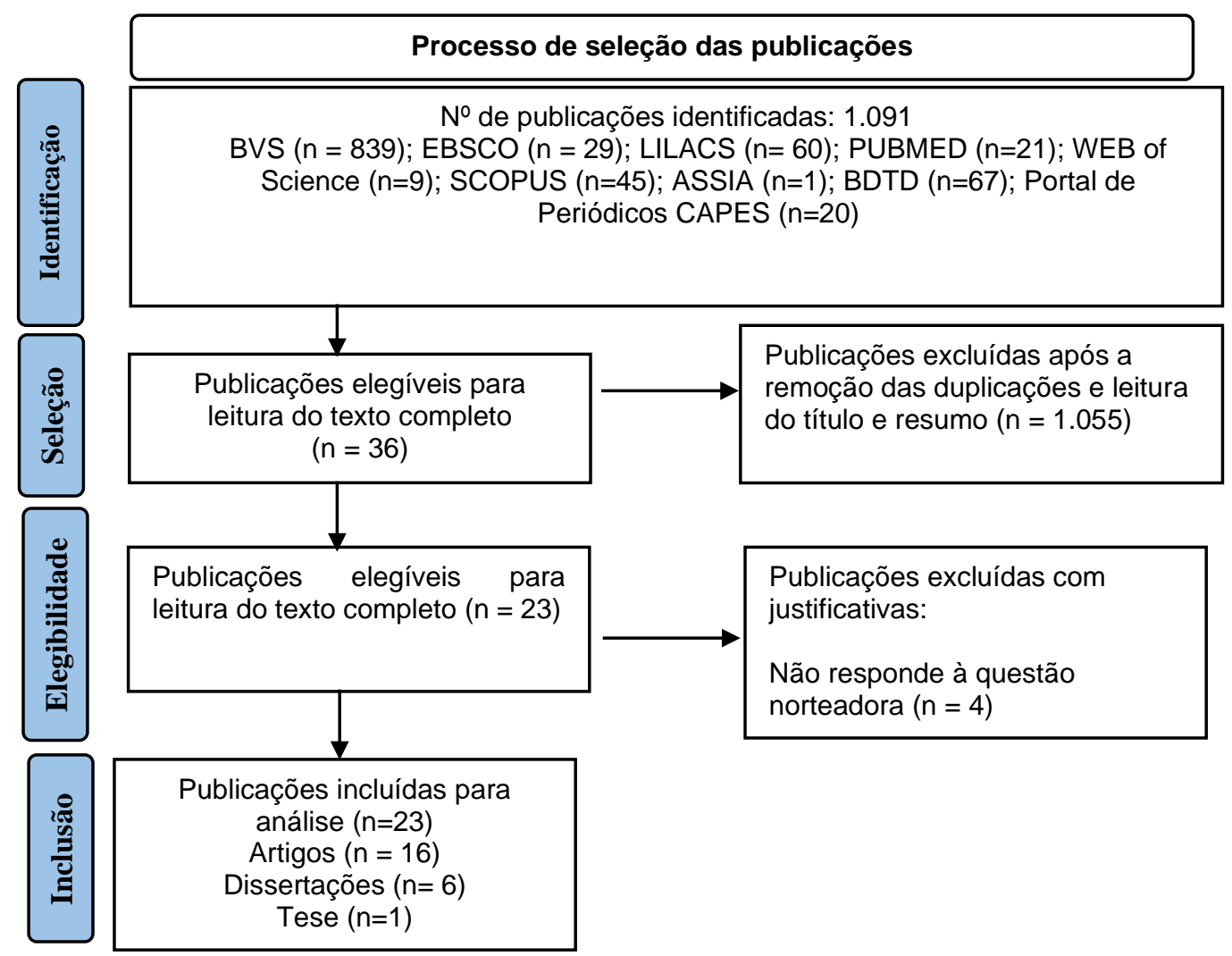

Fonte: Adaptado da figura Prisma, 2021 (PAGE et al.2021).

Na primeira etapa os estudos recuperados nas bases de dados, foram exportados para um gerenciador de referência (software ENDNOTE versão web), onde foi realizada a remoção das duplicações e foi feito a leitura do título e do resumo por um revisor, após a seleção, já na segunda etapa os textos foram lidos na íntegra considerando a exclusão dos estudos que não atenderam aos critérios de elegibilidade. Ao final os estudos incluídos foram lidos na íntegra pelo autor principal e revisado por um coautor. A discordâncias foram resolvidas por consenso usando os critérios de inclusão e exclusão pré-definidos e, no caso de discordância, a decisão final foi realizada por um terceiro revisor. Na sequência, as publicações foram agrupadas e categorizadas. A seguir apresentam-se as categorias construídas, referendando o estado da arte (Sousa, et al., 2018).

\section{Resultados}

Foram identificados 1.091 registros sobre o tema nas bases de dados pesquisadas e, após a exclusão das duplicadas, foram rastreados 70 registros. Ao final da leitura na íntegra de 36 publicações distribuídas nas bases de dados BVS, Descubra, Lilacs e SciELO, BDTD Nacional e CAPES, 23 delas foram incluídas na análise.

No Quadro 2 são apresentados os artigos indexados, oito $(53,3 \%$; 8/15) foram publicados em periódicos da Região Sudeste, seguidos de seis publicados na Região Nordeste (40\%, 6/15), e um foi publicado em periódico da Espanha $(66,6 \%$ 
1/15). Foram considerados 15 artigos científicos indexados, uma publicação em anais de evento científico, seis dissertações e uma tese.

Com relação ao cenário dos estudos, 19 foram realizados em comunidades quilombolas, sendo 12 em comunidades localizadas na Região Nordeste, quatro na Região Sul, dois na Região Sudeste e um na Região Norte do país. Vale destacar que um estudo não foi pesquisa de campo, e um mesmo autor, além de divulgar sua dissertação, publicou os resultados de sua pesquisa em três periódicos diferentes (Quadro 2).

Dentre os artigos científicos indexados segundo o ano das publicações (Figura 1), observa-se maior incidência (40\%) no ano de 2018 (6/15); 33,3\% no ano de 2016 (5/15); e 26,6\% foram publicados nos anos de 2010 a 2015 (4/15).

Quanto às abordagens metodológicas (Quadro 1), os desenhos de pesquisa encontrados foram: pesquisa qualitativa $(73,9 \% ; 17 / 23)$, pesquisa quantitativa $(13 \% ; 3 / 23)$, pesquisa quanti-qualitativa $(8,6 \% ; 2 / 23)$ e de revisão da literatura $(4,3 \%$; 1/23). Em relação às fontes utilizadas para as análises de dados, prevaleceram aquelas do tipo de conteúdo $(60,8 \% ; 14 / 23)$, descritiva $(21,7 \% ; 5 / 23)$ e teórica $(17,3 \%, 4 / 23)$.

Em 19 artigos $(82,6 \%$; 19/23) foram utilizadas fontes primárias, por meio de entrevistas, questionários, grupos focais e círculos de cultura. Em um artigo $(4,3 \% ; 1 / 23)$, foram utilizadas fontes secundárias, entre as quais buscas na literatura, documentos em bases de dados públicas. Os outros três artigos $(13 \% ; 3 / 23)$ utilizaram tanto fontes primárias quanto secundárias (Quadro 2). 
Quadro 2. Publicações selecionadas segundo autores, ano de publicação, tipo de periódico e localização do cenário do estudo período 2008 entre 2018

\begin{tabular}{|c|c|c|c|c|}
\hline Título do artigo & $\begin{array}{l}\text { Tipo de publicação - Periódico } \\
\text { (Estado) }\end{array}$ & Cenário do estudo & $\begin{array}{c}\text { Desenho da pesquisa - Técnica } \\
\text { de coleta dos dados }\end{array}$ & Tipo de análise \\
\hline $\begin{array}{l}\text { Características socioeconômicas e de saúde de um } \\
\text { grupo de mulheres de uma comunidade quilombola } \\
\text { (Prates, } \text { et al.,2018a) }\end{array}$ & $\begin{array}{l}\text { Artigo - Revista Mineira de } \\
\text { Enfermagem (Minas Gerais) }\end{array}$ & $\begin{array}{l}\text { Comunidade quilombola do interior do } \\
\text { Estado do Rio Grande do Sul }\end{array}$ & $\begin{array}{l}\text { Abordagem qualitativa - Grupo } \\
\text { Focal }\end{array}$ & $\begin{array}{l}\text { Análise de } \\
\text { conteúdo }\end{array}$ \\
\hline $\begin{array}{l}\text { Comunidade quilombola na Região Nordeste do } \\
\text { Brasil: saúde de mulheres e crianças antes e após } \\
\text { sua certificação (Ferreira \& Torres, 2015) }\end{array}$ & $\begin{array}{l}\text { Artigo - Revista Brasileira de Saúde } \\
\text { Materno Infantil } \\
\text { (Pernambuco) }\end{array}$ & $\begin{array}{l}\text { Comunidade quilombola de } \quad \text { Bom } \\
\text { Despacho, no Nordeste do Brasil }\end{array}$ & $\begin{array}{l}\text { Abordagem quantitativa/ } \\
\text { Questionário - Inquéritos } \\
\text { existentes em bases de dados }\end{array}$ & Comparativa \\
\hline $\begin{array}{l}\text { Práticas de cuidado de parteiras e mulheres } \\
\text { quilombolas à luz da antropologia interpretativa. } \\
\text { (Bonfim, et al., 2018) }\end{array}$ & $\begin{array}{l}\text { Artigo - Revista Brasileira de } \\
\text { Promoção da Saúde (Ceará) }\end{array}$ & $\begin{array}{l}\text { Comunidade quilombola do povoado de } \\
\text { Lagoinha de São Gabriel, no sertão } \\
\text { produtivo do Estado da Bahia }\end{array}$ & $\begin{array}{l}\text { Abordagem Qualitativa - } \\
\text { Entrevista semiestruturada }\end{array}$ & $\begin{array}{l}\text { Análise de } \\
\text { conteúdo }\end{array}$ \\
\hline $\begin{array}{l}\text { Utilização de serviços de saúde por população } \\
\text { quilombola do Sudoeste da Bahia, Brasil (Gomes, et } \\
\text { al.,2013) }\end{array}$ & $\begin{array}{l}\text { Artigo - Caderno de Saúde Pública } \\
\text { (Rio de Janeiro) }\end{array}$ & $\begin{array}{l}\text { Comunidades quilombolas da região de } \\
\text { Vitória da Conquista no Estado da Bahia } \\
\text { (Corta Lote, Maria Clemência, Furadinho, } \\
\text { Lagoa de Melquíades e Boqueirão) }\end{array}$ & $\begin{array}{l}\text { Abordagem quantitativa - } \\
\text { Questionário semiestruturado }\end{array}$ & Descritiva \\
\hline $\begin{array}{l}\text { A saúde entre o minoritário e o global: questões } \\
\text { identitárias entre mulheres quilombolas (Valentim, } \\
\text { 2016) }\end{array}$ & $\begin{array}{l}\text { Artigo - Psicologia e Saber Social } \\
\text { (Rio de Janeiro) }\end{array}$ & $\begin{array}{l}\text { Comunidades quilombolas do Estado do } \\
\text { Espírito Santo (Santana; Córrego Chiado; } \\
\text { Nova Vista; Angelim, Linharinho, São } \\
\text { Domingos; Angelim) }\end{array}$ & $\begin{array}{l}\text { Abordagem qualitativa e } \\
\text { Descritiva - Grupo Focal }\end{array}$ & $\begin{array}{l}\text { Análise de } \\
\text { conteúdo }\end{array}$ \\
\hline $\begin{array}{l}\text { Mulheres quilombolas e divisão sexual do trabalho } \\
\text { na sociedade contemporânea (Grossi, Oliveira \& } \\
\text { Bitencourt, 2018) }\end{array}$ & $\begin{array}{l}\text { Anais de congresso - } 6^{\circ} \text { Encontro } \\
\text { Internacional de Política Social e } 13^{\circ} \\
\text { Encontro Nacional de Política } \\
\text { Social/Espírito Santo }\end{array}$ & $\begin{array}{l}\text { Quilombos urbanos e rurais do Estado do } \\
\text { Rio Grande do Sul (Areal da Baronesa, } \\
\text { Alto do Caixão, Beco dos Colodianos, } \\
\text { Casca, Fidélix, Limoeiro, Chácara das } \\
\text { Rosas). }\end{array}$ & $\begin{array}{l}\text { Abordagem Qualitativa e } \\
\text { exploratório - Grupo Focal }\end{array}$ & $\begin{array}{l}\text { Análise de } \\
\text { conteúdo }\end{array}$ \\
\hline $\begin{array}{l}\text { Mama África: os quilombos do sertão e as lutas das } \\
\text { mulheres das comunidades de Catolé do Rocha-PB } \\
\text { (Souza, 2017) }\end{array}$ & $\begin{array}{l}\text { Dissertação - Universidade Federal da } \\
\text { Paraíba (Rio Grande do Norte) }\end{array}$ & $\begin{array}{l}\text { Comunidades quilombolas de Catolé do } \\
\text { Rocha (Pau de Leite, São Pedro dos } \\
\text { Miguéis, Lagoa Rasa e Curralinho/Jatobá) }\end{array}$ & $\begin{array}{l}\text { Abordagem quanti-qualitativa - } \\
\text { Entrevistas e Grupo focal }\end{array}$ & $\begin{array}{l}\text { Análise de } \\
\text { conteúdo }\end{array}$ \\
\hline $\begin{array}{l}\text { Ser mulher quilombola: revelando sentimentos e } \\
\text { identidades. Being a quilombola woman: unveilling } \\
\text { feelings and identities (Prates et al, 2018b) }\end{array}$ & $\begin{array}{l}\text { Artigo - Revista online de pesquisa } \\
\text { Cuidado É Fundamental (Rio de } \\
\text { Janeiro) }\end{array}$ & $\begin{array}{l}\text { Comunidade quilombola, no interior do } \\
\text { Estado do Rio Grande do Sul }\end{array}$ & $\begin{array}{l}\text { Abordagem qualitativa - } \\
\text { Entrevistas semiestruturadas }\end{array}$ & $\begin{array}{l}\text { Análise de } \\
\text { conteúdo }\end{array}$ \\
\hline $\begin{array}{l}\text { Território de afetos: o cuidado nas práticas } \\
\text { femininas quilombolas contemporâneas do Rio de } \\
\text { Janeiro (Almeida, 2016) }\end{array}$ & $\begin{array}{l}\text { Artigo - Transversos: Revista de } \\
\text { História (Rio de Janeiro) }\end{array}$ & $\begin{array}{l}\text { Comunidades quilombolas do Rio de } \\
\text { Janeiro: Bracuí (Angra dos Reis); } \\
\text { Campinho da Independência (Paraty); } \\
\text { Tapera (Petrópolis); Boa Esperança (Areal); } \\
\text { Maria Conga (Mãe); Sacopã (Rio de } \\
\text { Janeiro); Maria Joaquina (Cabo Frio). }\end{array}$ & $\begin{array}{l}\text { Abordagem qualitativa - Grupo } \\
\text { Focal }\end{array}$ & Análise teórica \\
\hline
\end{tabular}


Research, Society and Development, v. 11, n. 2, e42111225983, 2022

(CC BY 4.0) | ISSN 2525-3409 | DOI: http://dx.doi.org/10.33448/rsd-v11i2.25983

\begin{tabular}{|c|c|c|c|c|}
\hline $\begin{array}{l}\text { Vivenciando o Racismo e a Violência: um estudo } \\
\text { sobre as vulnerabilidades da mulher negra e a busca } \\
\text { de prevenção do HIV/aids em comunidades } \\
\text { remanescentes de Quilombos, em Alagoas } \\
\text { (Riscado, Oliveira \& Brito, 2010) }\end{array}$ & $\begin{array}{l}\text { Artigo - Revista Saúde e Sociedade } \\
\text { (São Paulo) }\end{array}$ & Comunidades quilombolas de Alagoas. & $\begin{array}{l}\text { Abordagem qualitativa - } \\
\text { Grupos Focais, entrevistas }\end{array}$ & $\begin{array}{l}\text { Análise de } \\
\text { conteúdo }\end{array}$ \\
\hline $\begin{array}{l}\text { Mulheres quilombolas, violência e as } \\
\text { interseccionalidades de gênero, etnia, classe social e } \\
\text { geração (Grossi, Oliveira \& Bitencourt, 2018). }\end{array}$ & $\begin{array}{l}\text { Artigo - Revista de Políticas Públicas } \\
\text { (Maranhão) }\end{array}$ & $\begin{array}{l}\text { Comunidades quilombolas do Rio Grande } \\
\text { do Sul (quilombos Chácara das Rosas, } \\
\text { Fidelix, Areal da Baronesa, Limoeiro, Beco } \\
\text { dos Colodianos) }\end{array}$ & $\begin{array}{l}\text { Abordagem qualitativa - } \\
\text { Entrevistas, documentos públicos }\end{array}$ & $\begin{array}{l}\text { Análise de } \\
\text { conteúdo }\end{array}$ \\
\hline $\begin{array}{l}\text { Mulheres quilombolas: território, gênero e } \\
\text { identidade na comunidade negra Senhor do Bonfim } \\
\text { (Santos, 2018) }\end{array}$ & $\begin{array}{l}\text { Dissertação - Universidade Federal da } \\
\text { Paraíba (Rio Grande do Norte) }\end{array}$ & $\begin{array}{l}\text { Comunidade Quilombola Senhor do } \\
\text { Bonfim, na Paraíba }\end{array}$ & $\begin{array}{l}\text { Abordagem qualitativa - Pesquisa } \\
\text { bibliográfica, observações de } \\
\text { campo, entrevistas, questionário } \\
\text { semi-estruturado }\end{array}$ & Análise teórica \\
\hline $\begin{array}{l}\text { Promoção da saúde das mulheres quilombolas: a } \\
\text { relação com os determinantes sociais (Durand, } \\
\text { 2016) }\end{array}$ & $\begin{array}{l}\text { Tese - Universidade Federal de Santa } \\
\text { Catarina, Programa de Pós-Graduação } \\
\text { em Enfermagem (Santa Catarina) }\end{array}$ & $\begin{array}{l}\text { Comunidade quilombola de Garopaba, no } \\
\text { Estado de Santa Catarina }\end{array}$ & $\begin{array}{l}\text { Abordagem qualitativa - Círculo } \\
\text { de Cultura (Itinerário de Pesquisa } \\
\text { de Paulo Freire) }\end{array}$ & $\begin{array}{l}\text { Análise de } \\
\text { conteúdo }\end{array}$ \\
\hline $\begin{array}{l}\text { O olhar feminino sobre o cuidado à saúde da mulher } \\
\text { quilombola (Prates, 2015) }\end{array}$ & $\begin{array}{l}\text { Dissertação - Universidade Federal } \\
\text { de Santa Maria. Programa de Pós- } \\
\text { Graduação em Enfermagem (Rio } \\
\text { Grande do Sul) }\end{array}$ & $\begin{array}{l}\text { Comunidade quilombola do interior do Rio } \\
\text { Grande do Sul }\end{array}$ & $\begin{array}{l}\text { Abordagem qualitativa e } \\
\text { descritiva - Grupo focal, } \\
\text { entrevista semiestruturada, diário } \\
\text { de campo }\end{array}$ & $\begin{array}{l}\text { Análise de } \\
\text { conteúdo }\end{array}$ \\
\hline $\begin{array}{l}\text { Promoção à saúde da mulher negra no povoado } \\
\text { Castelo, município de Alcântara, Maranhão, Brasil. } \\
\text { (Viegas \& Varga, 2016) }\end{array}$ & $\begin{array}{l}\text { Artigo - Revista Saúde e Sociedade } \\
\text { (São Paulo) }\end{array}$ & $\begin{array}{l}\text { Comunidade quilombola do município de } \\
\text { Alcântara no Estado do Maranhão }\end{array}$ & $\begin{array}{l}\text { Abordagem qualitativa - Pesquisa } \\
\text { bibliográfica, pesquisa } \\
\text { documental, questionário }\end{array}$ & $\begin{array}{l}\text { Análise de } \\
\text { conteúdo }\end{array}$ \\
\hline $\begin{array}{l}\text { Health survey in Quilombola communities } \\
\text { (descendants of Afro-Brazilian slaves who escaped } \\
\text { from slave plantations that existed in Brazil until } \\
\text { abolition in 1888) in Vitória da Conquista in the } \\
\text { state of Bahia: methodological aspects and } \\
\text { descriptive analysis (Bezerra et al., 2014) }\end{array}$ & $\begin{array}{l}\text { Artigo - Revista Ciência Saúde } \\
\text { Coletiva (Rio de Janeiro) }\end{array}$ & $\begin{array}{l}\text { Comunidades quilombolas de Vitória da } \\
\text { Conquista no Estado da Bahia, Brasil }\end{array}$ & $\begin{array}{l}\text { Abordagem quantitativa - } \\
\text { Questionário (Inquéritos } \\
\text { existentes em bases de dados) }\end{array}$ & $\begin{array}{l}\text { Análise de } \\
\text { conteúdo }\end{array}$ \\
\hline $\begin{array}{l}\text { Health conditions in quilombola communities las } \\
\text { condiciones de salud en las comunidades } \\
\text { quilombola (Cardoso, Melo \& Freitas, 2018) }\end{array}$ & $\begin{array}{l}\text { Artigo - Revista Journal of Nursing } \\
\text { UPE on line (Pernambuco) }\end{array}$ & $\begin{array}{l}\text { Pesquisa que utilizou dados secundários de } \\
\text { outros estudos. }\end{array}$ & Revisão integrativa da literatura & $\begin{array}{l}\text { Análise descritiva } \\
\text { e estatística }\end{array}$ \\
\hline $\begin{array}{l}\text { Experiências de mulheres quilombolas com } \\
\text { planejamento reprodutivo e assistência no período } \\
\text { gravídico-puerperal (Pereira et al, 2016) }\end{array}$ & Artigo - Revista Feminismos (Bahia) & $\begin{array}{l}\text { Comunidade de Porto da Pedra no } \\
\text { município de Maragogipe, no Estado da } \\
\text { Bahia }\end{array}$ & $\begin{array}{l}\text { Abordagem qualitativa, } \\
\text { exploratória, descritiva - } \\
\text { Entrevista semiestruturada }\end{array}$ & $\begin{array}{l}\text { Análise descritiva } \\
\text { (não } \\
\text { experimental) }\end{array}$ \\
\hline
\end{tabular}


Research, Society and Development, v. 11, n. 2, e42111225983, 2022

(CC BY 4.0) | ISSN 2525-3409 | DOI: http://dx.doi.org/10.33448/rsd-v11i2.25983

\begin{tabular}{|c|c|c|c|c|}
\hline $\begin{array}{l}\text { Itinerários terapêuticos de Quilombolas: um olhar } \\
\text { bioético sobre a atenção e o cuidado à saúde } \\
\text { (Prudêncio, 2017) }\end{array}$ & $\begin{array}{l}\text { Tese - Universidade Federal de } \\
\text { Santa Catarina, Programa de Pós- } \\
\text { Graduação em Saúde Coletiva (Santa } \\
\text { Catarina) }\end{array}$ & $\begin{array}{l}\text { Comunidades quilombolas do municipio de } \\
\text { Macapá (Curiaú de Fora, Curiaú de Dentro, } \\
\text { Curiaú de Fora, Casa Grande, Curralinho, } \\
\text { Extrema, Curiaú Mirim) }\end{array}$ & $\begin{array}{l}\text { Pesquisa de Abordagem } \\
\text { qualitativa - Mapeamento do } \\
\text { campo, observação participante, } \\
\text { diário de campo, entrevista }\end{array}$ & $\begin{array}{l}\text { Análise de } \\
\text { conteúdo }\end{array}$ \\
\hline $\begin{array}{l}\text { Natureza de mulher, nome de mãe, marca de negra: } \\
\text { identidades em trãnsito e políticas do corpo na } \\
\text { comunidade quilombola de Boa Vista dos Negros } \\
\text { (Boschemeier, 2010) }\end{array}$ & $\begin{array}{l}\text { Dissertação - Universidade Federal } \\
\text { do Rio Grande do Norte, mestrado em } \\
\text { Antropologia Social (Rio Grande do } \\
\text { Norte) }\end{array}$ & $\begin{array}{l}\text { Comunidade quilombola de Boa Vista dos } \\
\text { Negros, no Estado do Rio Grande do Norte }\end{array}$ & $\begin{array}{l}\text { Abordagem quanti-qualitativa - } \\
\text { Entrevista, observações } \\
\text { participantes }\end{array}$ & $\begin{array}{l}\text { Análise de } \\
\text { Conteúdo }\end{array}$ \\
\hline $\begin{array}{l}\text { Práticas preventivas para o câncer do colo uterino: } \\
\text { um estudo com mulheres quilombolas (Sorte,2015) }\end{array}$ & $\begin{array}{l}\text { Dissertação - Universidade Federal } \\
\text { da Bahia (Bahia) }\end{array}$ & $\begin{array}{l}\text { Comunidade quilombola Araçá-Cariacá, no } \\
\text { município de Bom Jesus da Lapa, no } \\
\text { Estado da Bahia. }\end{array}$ & $\begin{array}{l}\text { Abordagem qualitativa e } \\
\text { descritiva - Observação- } \\
\text { participação-reflexão, entrevista } \\
\text { semiestruturada. }\end{array}$ & Análise descritiva \\
\hline $\begin{array}{l}\text { Fatores que influenciam na prevenção do câncer do } \\
\text { colo do útero na comunidade quilombola (Jacintho } \\
\text { et al, 2018) }\end{array}$ & $\begin{array}{l}\text { Revista - Cultura de los Cuidados } \\
\text { (Espanha) }\end{array}$ & $\begin{array}{l}\text { Comunidade quilombola do Muquém, } \\
\text { localizada em União dos Palmares, no } \\
\text { Estado de Alagoas }\end{array}$ & $\begin{array}{l}\text { Abordagem qualitativa, descritiva } \\
\text { e etnográfica / Formulário, diário } \\
\text { de campo, } \\
\text { entrevistas }\end{array}$ & Análise teórica \\
\hline $\begin{array}{l}\text { Características socioeconômicas e de saúde de um } \\
\text { grupo de mulheres de uma comunidade quilombola } \\
\text { (Prates et al., 2016) }\end{array}$ & $\begin{array}{l}\text { Revista de Enfermagem UFPE on line } \\
\text { e (Pernambuco) }\end{array}$ & $\begin{array}{l}\text { Comunidade quilombola, localizada no Sul } \\
\text { do Brasil }\end{array}$ & $\begin{array}{l}\text { Abordagem qualitativa, descritiva } \\
\text { e etnográfica - Entrevista } \\
\text { individual semiestruturada }\end{array}$ & Análise teórica \\
\hline
\end{tabular}

Fonte: Elaboração própria a partir das fontes citadas (2020). 


\section{Discussão}

A discussão será apresentada em duas categorias que agregam os principais resultados das publicações incluídas sobre as necessidades de cuidado à saúde da mulher quilombola na perspectiva da interseccionalidade gênero, raça, corpo e política no cenário brasileiro

\section{Ser mulher quilombola no contexto social e político, na perspectiva da interseccionalidade gênero, raça, corpo e política}

A diáspora negra vivida pelas comunidades remanescentes do quilombo é um espelho no qual, na atualidade, aparecem refletidas as marcas de um racismo iniciado desde o Brasil Colônia. Seus territórios existenciais continuam longínquos, de difícil acesso, com uma população esquecida, deixada à margem, e são as mulheres, vozes da comunidade, que denunciam: um serviço de saúde distante da comunidade e onde encontram dificuldade de acesso; faltam políticas públicas; há descrédito e desvalorização de seus saberes ancestrais. Além disso, estas mulheres, em sua maioria, não são contempladas com a implementação das ações das políticas de assistência social, e quando questionadas sobre os aparatos culturais típicos de uma tradição ancestral negra, não se reconhecem como membros de uma comunidade quilombola (Araújo et al. 2020). Algumas se reconhecem como moradoras de uma comunidade rural (Viegas \& Varga, 2016; Prudêncio, 2017; Boschemeier, 2010). Por vezes, o desconhecimento da representatividade cultural da mulher quilombola e a falta de espaços igualitários aumenta as lacunas e dificultam o acesso a políticas sociais específicas para essa população, conforme identificado no estudo de Araújo et al (2020), realizado no grupo Dandara na comunidade quilombola Sussuaranade Piripiri no estado do Piauí.

A memória dessas mulheres, bem como suas identidades, está atrelada ao lugar onde vivem, guiadas por suas lembranças e onde desenvolvem um modo de vida, de sociabilidade e de afetividade junto a seus parentes, esposos e amigos. Em suas narrativas, demonstram o orgulho do lugar onde moram e de serem agricultoras; de terem recebido pela oralidade o conhecimento ancestral do manuseio das plantas medicinais pelas rezadeiras ou benzedeiras, qualificação dada àquelas que realizam a cura através de seus rezos, também conhecidos como benzimentos; de poderem ter tido seus partos realizados por parteiras, que as acompanharam na gestação, parto até o puerpério, por meio de práticas de cuidados pautadas nas crenças e costumes culturais, utilizando recursos naturais e da invocação divina (Boschemeier, 2010; Santos, 2018; Valentim, 2016; Souza, 2017; Bonfim et al., 2018).

Estudos apontam que, dentre os elementos da constituição da identidade quilombola, uma característica comum nessas comunidades é ser matrilinear, tendo a mulher como centro do grupo. Em suas comunidades, organizam reuniões para juntas discutirem assuntos relacionados à saúde e às formas de tratamento usadas tradicionalmente por elas. Também recuperam as mnêmicas acerca da religião e do território, característica semelhante à encontrada nas comunidades africanas, com uma partilha de responsabilidades e privilégios, incluindo o poder decisório (Santos, 2018; Prates, 2015).

No entanto, apesar de transparecer que tais reuniões sejam traduções elementares de resistência e de uma função social pela manutenção de sua identidade perante seus ascendentes, em algumas narrativas das mulheres quilombolas identificou-se a sensação de uma incapacidade de transmissão desses mesmos valores à geração mais nova, o que tem, consequentemente, interferido em sua formação identitária (Oliveira, 2016).

Vem ocorrendo, no campo delimitado de alguns territórios quilombolas, o epistmicidio, a morte de seus saberes ancestrais, provocado pelas formas massificadamente tecnicista, globais e culturalmente indiferenciadas, provenientes da comunicação em massa responsável pelo aculturamento nas formas de nascer, sentir, habitar, vestir e se expressar. Isso vem influenciando crianças e jovens tanto nos aspectos cognitivos e sociais, quanto na sua relação com o processo de constituição de uma alteridade, que não havia sido vivenciada com relação a seus antepassados. O direito à identidade e ao reconhecimento de sua cultura está expresso na Constituição Federal, e sua violação constitui uma forma de violência. Essa violência 
Research, Society and Development, v. 11, n. 2, e42111225983, 2022

(CC BY 4.0) | ISSN 2525-3409 | DOI: http://dx.doi.org/10.33448/rsd-v11i2.25983

simbólica, invisibilizada, silenciosa, causa marcas profundas na subjetividade dessas mulheres e atinge várias gerações, desde pessoas idosas, adultos, jovens, adolescentes e crianças (Grossi, Oliveira \& Oliveira, 2018; Valentim, 2016; Almeida, 2016).

Nas comunidades quilombolas, predomina a agricultura de subsistência; muitas mulheres trabalham na roça, de onde retiram o alimento de suas famílias. No entanto, em seus territórios, a falta de terra gera um processo de vulnerabilidade social, uma vez que, por conta de viverem em um espaço limitado e precário de moradia, as mulheres relatam que muitas vezes membros de sua família se deslocam para outros territórios, para grilagem. Em suas narrativas, sendo elas mães e/ou esposas, sofrem ao vivenciarem a saída de seus filhos e companheiros do território para procurar emprego ou cursos profissionalizantes. Eles migram, na maioria das vezes, para os grandes centros e vivenciam as dificuldades de acesso ao emprego formal, passam a residir em áreas distantes do local de trabalho, em condições precárias; e ainda, muitos abandonam a família (Grossi, Oliveira \& Oliveira, 2018; Souza, 2017; Bezerra et al., 2014).

As mulheres que optam por continuar no território assumem as decisões da casa, o que lhes confere maior autonomia e domínio sobre suas vidas, constituem as famílias matriarcais, nas quais o papel de resistência é um aparato socialmente determinado. Isso acontece porque muitas vezes, por terem seus cônjuges trabalhando fora, desempregados ou doentes, as mulheres quilombolas tornam-se as responsáveis pelo plantio e lida na roça, pela caça e ainda assumem os trabalhos domésticos e além do cuidado da saúde da família; são elas as responsáveis pela vida nas comunidades. Outras também buscam trabalho na cidade como terceirizadas, domésticas, muitas vezes em subempregos, sem carteira assinada; com isso deixam de seguir com os estudos e acabam se casando precocemente. Vivenciam o estigma da senzala e da cor de uma sociedade, que assume o papel de capataz, castigando-as com serviços penosos, preconceito e discriminação racial (Boschemeier, 2010; Santos, 2018; Souza, 2017; Almeida, 2016; Grossi, Oliveira \& Bitencourt, 2018; Prates, et al.,2018a).

Outras pesquisas apontam que as mulheres, no cenário de alguns quilombos, sofrem ao perceberem os dispositivos racistas, sexistas e classistas que incidem sobre seus corpos e territórios, impondo um novo significado para o termo "quilombo" na contemporaneidade, mesclando práticas antirracistas e antissexistas a suas ações de luta pela terra (Rodrigues, Souza, Queiroz \& Nunes, 2021; Neto et al., 2022). No intuito de reconstruírem uma tradição por vezes silenciada, atuam na organização política e dinâmica de seus territórios. Algumas ocupam cargos de presidência de suas associações; outras exercem liderança por meio de ações e protagonismo, participando de reuniões com gestores públicos para solicitar melhorias para suas comunidades. Tais mulheres afirmam ser contrárias ao discurso da força da mulher negra, uma vez que o que está posto é a necessidade de serem fortes para suportarem a opressão, o que é diferente de superá-la. Assim, estão engajadas em lutar por sua saúde e contra o epistemicídio, reunindo-se em espaços de solidariedade e de transmissão de experiências; dizem não ao desrespeito por seus corpos, saberes e territórios, ampliando a resistência e ressignificando a potência e o valor da vida (Prates et al, 2018a; Almeida, 2016).

A tradição do cuidado exercido pelas mulheres quilombolas rasura a noção da experiência quilombola pensada há anos exclusivamente por meio da força e da virilidade e reforça o desempenho da maternagem praticada por essas mulheres. Essa tradição, somada a todos os afazeres desempenhados por elas no papel de agricultoras, donas de casa, mães, provedoras do lar, são os motivos pontuados nos estudos sobre suas narrativas para se esquecerem de si e só cuidar dos outros com os quais se relaciona no emaranhado de afeto presente em seu território (Viegas \& Varga, 2016; Santos,2018; Prates, 2015; Grossi, Oliveira \& Bitencourt, 2018)

Segundo Rodrigues, Souza, Queiroz \& Nunes (2021), os quilombos formam atualmente um movimento de busca e luta pela terra, e essa luta também é reconstruída cotidianamente, sobretudo pelo precário acesso às políticas públicas e pelos conflitos de terras com os latifundiários. Em termos de políticas públicas, os estudos apontam que no Governo Lula as mulheres quilombolas tiveram acesso à água, através das construções de cisternas (Prudêncio, 2017; Souza, 2017; Bezerra et 
al., 2014). Antes, desta iniciativa deste governo, as famílias carregavam latas d'água na cabeça para poder beber e cozinhar, por longas distâncias até suas residências, uma vez que a água do açude era utilizada para tomar banho, lavar as roupas, regar plantas, para o cultivo de peixes e para os animais. As pesquisas destacam ainda outros benefícios sociais que impactaram na saúde e na vida destas mulheres, como por exemplo a construção de banheiros e fossas nas casas daqueles que ainda não tinham banheiro; a cesta básica; e o bolsa família, que muitas vezes é a única fonte de renda de suas famílias (Prudêncio, 2017; Souza, 2017; Bezerra et al., 2014).

As mulheres quilombolas, pelo fato de serem negras, também carregam o mito de inferioridade sobre sua etnia e, na maioria das vezes, ainda apresentam situação econômica desfavorável, o que intensifica sua condição e as desigualdades vivenciadas (Neto et al., 2022). Essas condições se associam às relações de poder que demarcam as possibilidades e impossibilidades de apropriação de determinados recursos materiais e simbólicos pelas mulheres negras. As tensões permanentes entre políticas de igualdade e políticas de equidade colocam desafios à garantia dos direitos à saúde dessas populações (Viegas \& Varga, 2016; Santos,2018; Prates, 2015; Grossi, Oliveira \& Bitencourt, 2018; Prates et al., 2018b).

Essas mulheres quilombolas vivenciam a interseccionalidade - ou seja, sistemas discriminatórios de opressões, tanto social quanto política, de classe, gênero, de raça e etnia - que intensificam as iniquidades, por serem marcadores sociais da diferença, e demarcam as possibilidades e impossibilidades de apropriação de determinados recursos materiais e simbólicos. Contudo, as múltiplas opressões existenciais por elas vivenciadas reduzem as chances do exercício pleno de sua própria cidadania. A interseccionalidade dispende energia dessas mulheres e reforça a necessidade de união, de uma luta coletiva em seus diferentes modos de resistir e nos mais diversos espaços de poder (Viegas \& Varga, 2016; Prates, 2015; Grossi, Oliveira $\&$ Bitencourt, 2018; Prates et al. 2018a; Santos, 2018).

\section{Mulher quilombola e as necessidades de cuidado em relação ao seu corpo, levando em conta seu estado de vulnerabilidade e o contexto de negação de direitos}

O conceito de gênero é considerado uma construção histórica e desigual atrelada a um processo cultural que determina que papéis sociais devem ser desempenhados por homens e mulheres na sociedade. Estudos o apontam como o gênero é um fenômeno universal, presente nas relações de desigualdade e opressão vivenciadas pela população negra, particularmente pelas mulheres quilombolas. Estas expressam tal desigualdade de forma muito singular, uma vez que em suas narrativas se fazem presentes diversas formas de violência racial e de gênero, tanto no ambiente privado como no público (Prates et al. 2018b; Riscado, Oliveira \& Brito, 2010)

No âmbito privado, estudos revelam a violência doméstica no contexto das relações interpessoais, deixando marcas tanto físicas quanto psíquicas nos corpos dessas mulheres. São relatos de submissão ao patriarcado no transcurso de sua existência, de sofrimento, de culpa associados à vergonha de expor o fato de estarem sendo violentada em seus próprios lares e ficarem sujeitas ao julgamento das pessoas que convivem com elas naquele território, bem como angústia devido à dificuldade de romper com esse vínculo que lhes causa tanta dor. Nesse sentido, a violência é entendida como forma cruel e perversa que contribui para o aviltamento da dignidade do ser mulher. Uma forma perversa de controle e de poder masculino e de um sistema construído sob a ótica do patriarcalismo, machismo, racismo e sexismo, que impedem a mulher de construir sua alteridade (Valentim, 2016; Grossi, Oliveira \& Bitencourt, 2018; Riscado, Oliveira \& Brito, 2010).

No âmbito público, as mulheres sentem os efeitos devastadores do preconceito racial que sofrem em seu cotidiano em decorrência do racismo e do sexismo perpetrados contra elas no transcurso da história. Observou-se que as narrativas encontradas nos estudos incluídos nesta revisão, destacam o sofrimento emocional das mulheres quilombolas causados pelo 
Research, Society and Development, v. 11, n. 2, e42111225983, 2022

(CC BY 4.0) | ISSN 2525-3409 | DOI: http://dx.doi.org/10.33448/rsd-v11i2.25983

racismo indistintamente por conta da cor da pele, pelo cabelo e pelo lugar onde residem há muitas gerações (Prates, 2015, Prates et al., 2018b; Riscado, Oliveira \& Brito, 2010) . Essa situação excludente e de subalternidade, que em termos simbólicos coloca suas comunidades em posição de invisibilidade nos centros urbanos, criando um imaginário social de um lugar distante, de existência de ex-escravos, subalternizando esses grupos como folclóricos e enquadrando-os em cenários de involução (Boschemeier, 2010; Valentim, 2016; Souza, 2017; Prates, 2015, Prates et al., 2018b; Riscado, Oliveira \& Brito, 2010).

As mulheres quilombolas vivenciam dificuldades que são vistas como desafios a serem enfrentados no cuidado com a saúde, devido à ausência de um serviço de saúde local para atender integralmente a todos os moradores e à dificuldade de acesso aos serviços públicos de saúde, tanto pela distância quanto pela falta de recurso financeiro para custear o transporte até a unidade de saúde. Alguns estudos identificaram que esta carência de recursos, aumenta a dificuldade de acesso ao atendimento nas Unidades Básicas de Saúde da cidade, pelo fato de não serem moradoras daquela área de cobertura, ou pelo fluxo de atendimento estabelecido (Prates, 2015; Prates et al. 2018b; Gomes et al., 2013).

Muitos estudos apontam que as mulheres quilombolas possuem pouca visibilidade no escopo de políticas públicas de promoção e prevenção da saúde, uma vez que suas necessidades específicas de cuidado são ignoradas (Durand, 2016; Boschemeier, 2010; Grossi, Oliveira \& Bitencourt, 2018; Prates et al., 2016). Esse fato se configura em violações de direitos evidenciadas em indicadores de vulnerabilidade social, econômicos e de saúde, caracterizados pela desigualdade, pela exploração, pelas relações de poder que materializam a violência estrutural e institucional sofrida pelas mulheres quilombolas. Suas trajetórias são marcadas pela interação entre sistemas de opressão como racismo, sexismo, desigualdade econômica, patriarcado e epistemicídio, que culminam com a inferiorização das mulheres negras na sociedade (Durand, 2016; Boschemeier, 2010; Grossi, Oliveira \& Bitencourt, 2018; Prates et al., 2016; Riscado, Oliveira \& Brito, 2010; Cardoso, Melo \& Freitas, 2018).

Muitas comunidades quilombolas referendam que o modelo de atendimento ofertado é centrado no modelo biomédico. Os profissionais que atendem essas mulheres não avaliam integralmente e muito menos reconhecem o poder das plantas e a cultura local como aliados no tratamento. Por isso, muitas mulheres saem dos consultórios com prescrições de medicamentos, alguns deles indisponíveis na rede, o que as obriga a tirar dinheiro de onde não têm; elas acabam se endividando para poder comprar o medicamento prescrito, o que contribui para o descrédito no profissional de saúde que, na visão delas, exercem um cuidado rotineiro e despersonificado (Prudêncio, 2017; Prates, 2015; Prates et al., 2018b).

Para alcançar ou manter uma condição plena de saúde, as mulheres quilombolas deveriam ter acesso aos cuidados de promoção da saúde devem incluir ações de higiene no preparo dos alimentos e a prática da atividade física. Essa população necessita de orientações básicas sobre os cuidados na utilização de vasos sanitários públicos e sobre a importância da realização de exames para rastreamento do câncer de colo de útero e do câncer de mama. Os estudos detectaram que muitas mulheres quilombolas nunca tiveram acesso ao exame ginecológico, e ainda desconhecem a periodicidade e a idade em que esse acompanhamento deve ser realizado; para além disso as barreiras psicológicas como medo, vergonha, desconforto e sobretudo o preconceito e a falta de um atendimento humanizado dos profissionais de saúde, distanciam ainda mais essa mulher do seu direito de ter acesso aos serviços de promoção da saúde que são oferecidos no SUS (Valentim, 2016; Prates, 2015; Sorte, 2015; Jacintho et al., 2018; Pereira \& Ferreira, 2016).

Os estudos reforçam o total desconhecimento da mulher quilombola sobre a importância da utilização dos preservativos na relação sexual, o que as coloca em situação de vulnerabilidade para contrair infecções sexualmente transmissíveis (IST) e gravidez indesejada (Valentim, 2016; Prates, 2015; Sorte, 2015; Jacintho et al., 2018; Pereira \& Ferreira, 2016). Estudo realizado com mulheres de comunidades quilombolas do Nordeste revelou que $80 \%$ delas engravidaram com menos de 19 
anos, o que potencializa seu estado de vulnerabilidade social, que muitas vezes param de estudar, não se qualificam profissionalmente, além de serem desvalorizadas no mercado de trabalho (Ferreira \& Torre, 2015).

Ademais o sentimento de vergonha que essas mulheres quilombolas têm do próprio do corpo, pode estar relacionado com as influências dos padrões de beleza impostos pelo modelo ocidental e ideologicamente racista da estética branca, impactam negativamente na saúde desta população (Neto et al.,2022). Algo que potencializa a concepção da identidade do branco dominador, de valores repassados pela ideologia do embranquecimento e do mito da democracia racial (Riscado, Oliveira \& Brito, 2010).

O cuidado em saúde aparece nas pesquisas associado a proposições, crenças, valores e práticas resultantes do contexto cultural de sua comunidade, tendo como fim a manutenção da saúde, para conseguirem realizar suas atividades cotidianas, remetendo o cuidado às dimensões de ocupação e trabalho, elucidando o cuidado com a saúde como fundamental para a realização de alguma tarefa. O valor atribuído ao cuidado em saúde aparece diretamente relacionando com o desempenho de suas atividades laborais cotidianas, resultante da possibilidade de produzirem e contribuírem no contexto familiar ou comunitário. O cuidado em saúde e o trabalho mostraram-se estritamente ligados, sendo que, no quilombo, o primeiro é valorizado em função do segundo (Grossi, Oliveira \& Oliveira, 2018; Valentim, 2016; Prates, 2015; Prates et al., 2016; Prates et al. 2018b).

\section{Considerações Finais}

A diáspora negra no Brasil colonial consolida a genealogia do racismo que perdura ainda hoje. Com o olhar direcionado às mulheres quilombolas, as pesquisas delineiam as memórias de seus modos de vida e de sociedade que são centrais para a pensar no cuidado e na saúde desta população que ainda são invisíveis nas políticas de saúde. As narrativas, denunciam sofrimentos e conquistas, a saga da resistência diante das condições históricas de desemparo social e violência sofridas, dentro e fora do espaço comunitário, do público ao privado, que impõem barreiras ao seu desenvolvimento social e geram desigualdades ligadas à educação escolar, à seletividade do mercado de trabalho, à pobreza e às condições de saúde/adoecimento, que têm na base o apagamento cultural e a sobreposição da cultura de massas.

O resultado desta revisão expõe uma realidade desigual e precária das mulheres quilombolas no acesso aos cuidados em saúde, algo que deve ser alvo de debate e discussão entre profissionais de saúde e gestores em prol da melhoria no acesso as políticas de saúde da mulher no SUS. Adicionalmente espera-se sensibilizar os profissionais de saúde, acadêmicos e pesquisadores sobre as necessidades de cuidado e de saúde da mulher quilombola, para além do biológico, tendo em vista combater a opressão imposta sobre seus corpos, descontruir preconceitos e extinguir os reflexos negativos do estigma sobre sua saúde.

As iniquidades sociais vivenciadas pelas mulheres quilombolas refletem as opressões geradas pela interseccionalidade de seu cotidiano e reiteram a violência estrutural, institucional e cultural a que elas estão expostas. Tais formas de violência se materializam nas desigualdades étnico-raciais, no racismo, no patriarcado, no sexismo, na falta de acesso à saúde e na descaracterização dessa mulher como um ser de direito. Tudo isso demanda iniciativas das instâncias governamentais e sensibilidade dos profissionais de saúde, para fortalecer o direito destas mulheres a serviços de saúde de qualidade, resolutivo, humanizado, acessível, equitativo, democrático e que valorizem a cultura das mulheres quilombolas e respeite aos aspectos étnico-raciais envolvidos no processo do cuidado. 
Research, Society and Development, v. 11, n. 2, e42111225983, 2022

(CC BY 4.0) | ISSN 2525-3409 | DOI: http://dx.doi.org/10.33448/rsd-v11i2.25983

\section{Referências}

Almeida, M. (2016). Territórios dos afetos: O cuidado nas práticas femininas quilombolas contemporâneas do Rio de Janeiro. Revista Transversos, (8), 21834. $10.12957 /$ transversos.2016.26543

Araújo, M. J. da S., et al. (2020). Quilombola representations of the Dandara group of the Sussuarana community of Piripiri, Piauí, Brazil. Research, Society and Development, 9(7), e515974376. 10.33448/rsd-v9i7.4376.

Bezerra, V. M. et al. (2014). Health survey in Quilombola communities (descendants of Afro-Brazilian slaves who escaped from slave plantations that existed in Brazil until abolition in 1888) in Vitória da Conquista in the state of Bahia (COMQUISTA Project), Brazil: methodological aspects and descriptive analysis. Ciencia \& saude coletiva, 19(6), 1835-47. 10.1590/1413-81232014196.01992013.

Bonfim, J.O., Prado, I .F., Sorte, E. T. B., Couto, P. L. S., França, N. M. \& Gomes, A. M. T. Práticas de cuidado de parteiras e mulheres quilombolas à luz da antropologia interpretativa. Rev Bras Promoç Saúde. 2018 jul./set.;31(3),1-11. 10.5020/18061230.2018.7081

Boschemeier, A. G. E. (2010). Natureza de mulher, nome de mãe, marca de negra: identidades em trânsito e políticas do corpo na comunidade quilombola de Boa Vista dos Negros, Rio Grande do Norte. Brasil. Dissertação de mestrado. Rio Grande do Norte. https://repositorio.ufrn.br/bitstream/123456789/12263/1/NaturezaMulherNome_Boschemeier_2010.pdf

Cardoso, C. S., de Melo, L. O., \& Freitas, D. A. (2018). Health conditions in quilombola communities. Journal of Nursing UFPE on line, 12(4), 1037-45. 10.5205/1981-8963-v12i4a110258p1037-1045-2018

Casarin, S. T., Porto, A. R., Gabatz, R. I. B., Bonow, C. A., Ribeiro, J. P., \& Mota, M. S. (2020). Tipos de revisão de literatura: considerações das editoras do Journal of Nursing and Health. J. nurs. health. 10(5), e20104031.

Durand, M.K. (2016). Promoção da saúde das mulheres quilombolas: a relação com os determinantes sociais. Florianópolis, Brasil. Tese de doutorado. Rio Grande do Sul. https://repositorio.ufsc.br/xmlui/handle/123456789/175834

Fernandes, S. L., Galindo, D. C. G., \& Valencia, L. P. (2020). Quilombola identity: actuations in daily of women quilombolas in the agreste of Alagoas. Psicologia em Estudo [online]. 25, e45031. 1-15 10.4025/psicolestud.v25i0.45031

Ferreira, H. D. S., \& Torres, Z. M. C. (2015). Comunidade quilombola na Região Nordeste do Brasil: saúde de mulheres e crianças antes e após sua certificação. Revista Brasileira de Saúde Materno Infantil, 15(2),219-29.

Freitas, D. A. et al. (2011). Saúde e comunidades quilombolas: uma revisão da literatura. Revista Cefac, 13 (5), 937-43. 10.1590/S1516-18462011005000033

Melnyk, B. M., \& Fineout-Overholt, E. (Eds.). (2011). Evidence-based practice in nursing \& healthcare: A guide to best practice. Lippincott Williams \& Wilkins.

Gomes, K. D. O. et al. (2013). Utilização de serviços de saúde por população quilombola do Sudoeste da Bahia, Brasil. Cadernos de Saúde Pública, 29 (9), $1829-42.10 .1590 / 0102-311$ X00151412

Grossi, P. K., de Oliveira, S. B., \& Bitencourt, J. V. (2018). Mulheres quilombolas e divisão sexual do trabalho na sociedade contemporânea. Anais do Encontro Internacional e Nacional de Política Social, 1(1). https://periodicos.ufes.br/einps/article/view/20034/13367

Grossi, P. K., de Oliveira, S. B., \& da Luz Oliveira, J. (2018). Mulheres quilombolas, violência e as interseccionalidades de gênero, etnia, classe social e geração. Revista de Políticas Públicas, 22, 930-47. http://www.periodicoseletronicos.ufma.br/index.php/rppublica/article/download/9825/5781

Instituto Brasileiro de Geografia e Estatística. (2019). Censo Demográfico da população residente, por cor ou raça, segundo a situação do domicílio, o sexo e a idade. Brasília: IBGE.

Jacintho, K. S., et al. (2018). Fatores que influenciam na prevenção do câncer do colo do útero na comunidade quilombola. Cult. cuid, 22(50),151-57. https://pesquisa.bvsalud.org/portal/resource/pt/ibc-175567

Neto, L.J. et al. (2022). The principles of Good Living in the relationship with women's protagonism. Research, Society and Development, 11(1), e52311125508

Page, M. J., et al (2021). The PRISMA 2020 statement: an updated guideline for reporting systematic reviews. Bmj, 372 (71), 10.1136/bmj.n71

Paranhos, D. (2016). O papel da bioética no enfrentamento do racismo. Revista Brasileira De Bioética, 12 (1), 1-11. 10.26512/rbb.v12i0.7666.

Pereira, Jesus C. O., \& Ferreira, S. L. (2016). Experiências de mulheres quilombolas com planejamento reprodutivo e assistência no período gravídicopuerperal. Revista Feminismos, 4(23), 47-61. https://periodicos.ufba.br/index.php/feminismos/article/view/30198

Oliveira, D. J. P. C. (2016). Acesso e utilização de serviços de saúde por mulheres quilombolas para a promoção da saúde reprodutiva. Salvador, Brasil. Dissertação de mestrado. Bahia. https://repositorio.ufba.br/bitstream/ri/23866/1/DISSERTA\%c3\%87\%c3\%83O\%20CHIRLENE\%20OLIVEIRA.pdf

Prates, L. A., et al., (2018a). Ser mulher quilombola: revelando sentimentos e identidades. Revista Mineira de Enfermagem, 22, e-1098. 1-9. 10.5935/14152762.20180028

Prates, L. A., et al. (2018b). Significados Atribuídos por Mulheres Quilombolas ao Cuidado à Saúde. Revista de Pesquisa: Cuidado é Fundamental, 10(3), 847-55. 10.9789/2175-5361.2018.v10i3.847-855 
Research, Society and Development, v. 11, n. 2, e42111225983, 2022

(CC BY 4.0) | ISSN 2525-3409 | DOI: http://dx.doi.org/10.33448/rsd-v11i2.25983

Prates, L. A., et al. (2016). Características socioeconômicas e de saúde de um grupo de mulheres de uma comunidade quilombola. Rev Enferm UFPE [Internet], 10(1), 103-11. 10.5205/1981-8963-v10i1a10927p103-111-2016

Prates LA. (2015) O olhar feminino sobre o cuidado à saúde da mulher quilombola. Dissertação de Mestrado. Santa Maria, Brasil. Rio Grande do Sul. http://repositorio.ufsm.br/handle/1/7436

Prestes, C. R., \& Paiva, V. S. (2016). Abordagem psicossocial e saúde de mulheres negras: vulnerabilidades, direitos e resiliência1. Saúde e Sociedade, 25 (3), 673-88. 10.1590/S0104-129020162901

Prudêncio LS. (2017). Itinerários terapêuticos de Quilombolas: um olhar bioético sobre a atenção e o cuidado à saúde. Florianópolis, Brasil. Tese de Doutorado. Rio Grande do Sul. https://repositorio.ufsc.br/xmlui/handle/123456789/178311

Riscado, J. L. D. S., Oliveira, M. A. B. D., \& Brito, Â. M. B. B. D. (2010). Vivenciando o racismo e a violência: um estudo sobre as vulnerabilidades da mulher negra e a busca de prevenção do HIV/aids em comunidades remanescentes de Quilombos, em Alagoas. Saúde e Sociedade, 19(suppl 2): 96-108. $10.1590 / \mathrm{S} 0104-12902010000600010$

Rodrigues, T. de A., Souza, F. L. M., Queiroz, Z. F. de, \& Nunes, C. (2021). Between resistance, advances and setbacks: a socio-historic overview of quilombola communities in Brazil and in the Cariri region of Cearense. Research, Society and Development, 10(11), e551101120087. 10.33448/rsdv10i11.20087

Santos, G. S., (2018). Mulheres quilombolas: território, gênero e identidade na comunidade negra Senhor do Bonfim. Pernambuco, Brasil. Dissertação de Mestrado. Paraíba. https://repositorio.ufpb.br/jspui/handle/123456789/13215

Sorte, E. T. B. (2015). Práticas preventivas para o câncer do colo uterino: um estudo com mulheres quilombolas. Salvador. Brasil. Dissertação de Mestrado. Bahia. http://repositorio.ufba.br/ri/handle/ri/23566

Sousa, L. M. M., et al., (2018). Revisões da literatura científica: tipos, métodos e aplicações em enfermagem. Revista Portuguesa de Enfermagem de Reabilitação, 1(1), 45-54. 10.33194/rper.2018.v1.n1.07.4391

Souza, M. F. D. P. D., Silva, W. L. A. D., \& Costa, L. P. D. (2019). Comunidade Remanescente de Quilombo, desigualdade e política pública: reflexões sobre um 'caso particular do possível' das mulheres quilombolas em uma comunidade na região norte-rio-grandense. Interações (Campo Grande), 20 (4), 1057-71. 10.20435/inter.v20i4.2033

Souza, V. (2017). Mama África: os quilombos do sertão e as lutas das mulheres das comunidades de Catolé do Rocha-PB. Pernambuco, Brasil. Dissertação de Mestrado. Paraíba. https://repositorio.ufpb.br/jspui/handle/123456789/11831

Valentim, R. P. F. (2016). A saúde entre o minoritário e o global: questões identitárias entre mulheres quilombolas. Psicologia e Saber Social, 5(1): 68-67. 10.12957/psi.saber.soc.2016.18926

Viegas, D. P., \& Varga, I. V. D. (2016). Promoção à saúde da mulher negra no povoado Castelo, Município de Alcântara, Maranhão, Brasil. Saúde e Sociedade, 25 (3): 619-30. 10.1590/S0104-129020162577

Werneck, J. (2016). Racismo institucional e saúde da população negra. Saúde e Sociedade, 25 (3), 535-49. 10.1590/S0104-129020162610. 